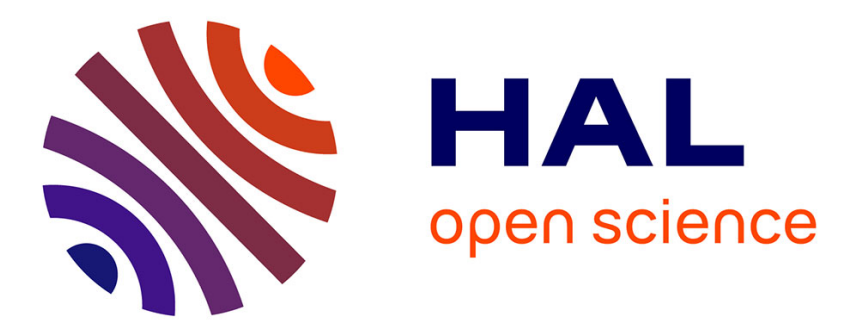

\title{
Time-Frequency Modelling of Near-Zone EM Coupling with Planar Circuit with NF/NF Transform \\ B. Ravelo
}

\section{To cite this version:}

B. Ravelo. Time-Frequency Modelling of Near-Zone EM Coupling with Planar Circuit with NF/NF Transform. EMC Europe 2014, Sep 2014, Gothenburg, Sweden. hal-02485767

\section{HAL Id: hal-02485767 \\ https://hal.science/hal-02485767}

Submitted on 24 Feb 2020

HAL is a multi-disciplinary open access archive for the deposit and dissemination of scientific research documents, whether they are published or not. The documents may come from teaching and research institutions in France or abroad, or from public or private research centers.
L'archive ouverte pluridisciplinaire HAL, est destinée au dépôt et à la diffusion de documents scientifiques de niveau recherche, publiés ou non, émanant des établissements d'enseignement et de recherche français ou étrangers, des laboratoires publics ou privés. 


\title{
Time-Frequency Modelling of Near-Zone EM Coupling with Planar Circuit with NF/NF Transform
}

\author{
B. Ravelo \\ IRSEEM EA 4353, ESIGELEC \\ Technopole du Madrillet, Av. Galilée, BP 10024, \\ 76801 Saint Etienne du Rouvray Cedex, France \\ e-mail: blaise.ravelo@esigelec.fr
}

\begin{abstract}
This paper is devoted on time-frequency EM coupling modelling between planar microwave device and grounded wire. The computational model is based on the timefrequency method with the combination BLT equation, nearfield/near-field (NF/NF) transform and FFT/IFFT operation on EM NF radiation with electrical fast transient excitation. The method was used for investigating coupling between $3 \mathrm{~cm}$ length metallic wire placed at some $\mathbf{m m}$ of microstrip Wilkinson power divider. From the scanned measured EM NF radiated at $3 \mathrm{~mm}$ above the power divider from $0.7 \mathrm{GHz}$ to $1.3 \mathrm{GHz}$, the voltage transfer coupling and the transient coupled voltages across the extremities of the victim wire were determined. The developed method is beneficial compared to 3D EM solver with its computation speed and flexibility to consider complex circuits under burst transient perturbations. The method can be potentially exploited for RF/microwave EMC engineering.

Keywords-BLT equation, near-field (NF) coupling, EMC analysis, transmission line theory, plane wave spectrum theory.
\end{abstract}

\section{INTRODUCTION}

The trends on multifunction integration in confined $\mathrm{RF} /$ microwave boards can be constrained by radiating nearfield (NF) EMC emission [1-2]. Facing to typically burst transient perturbations [3], various standards as IEC 61000-4-4 [4] and EN-55022 [5] were established notably owing to radio disturbances. Due to EM NF illuminations, different modelling methods [6-12] were proposed, for example, to assess the coupled voltages induced across transmission lines (TLs). The EM coupling onto TL was, at the beginning, calculated based on the consideration of both electrical $(\mathrm{E})$ and magnetic $(\mathrm{H})$ illuminating fields [7]. It was reduced to consideration of only E- [8][10] or H- [9] fields by calculating the induced voltage or current, respectively, along the victim line.

More recently, more generalized models were forwarded by considering a hybrid method [11] of aggression EM NF evaluation and the coupled voltage calculation and also the integration of plane wave spectrum (PWS) NF/NF transform [12]. But till now, those models are focused on frequency domain analysis. For this reason, an extension of this model by considering fast transient disturbances as IEEE C62.41:1991 and IEC 897:2004 ESD phenomena. For the better understanding, this paper is organized as follows. Section II is the methodological investigation. Section III describes application results. Section IV draws the conclusion.

\section{DESCRIPTION OF THE TIME-FREQUENCY NF COUPLING METHODOLOGY}

Fig. 1 presents the configuration of the $L_{x} \times L_{y}$ size radiating planar circuit placed at distance $z_{1}$ under the victim grounded wire. One supposes that the wire is with length $d$ and fixed at height $\left(z_{2}-z_{1}\right)$ on metallic ground (GND) plane. To determine the coupling voltages across the wire extremities $u(y=0)$ and $u(y=d)$, we use the NF/NF transform as introduced in [13]

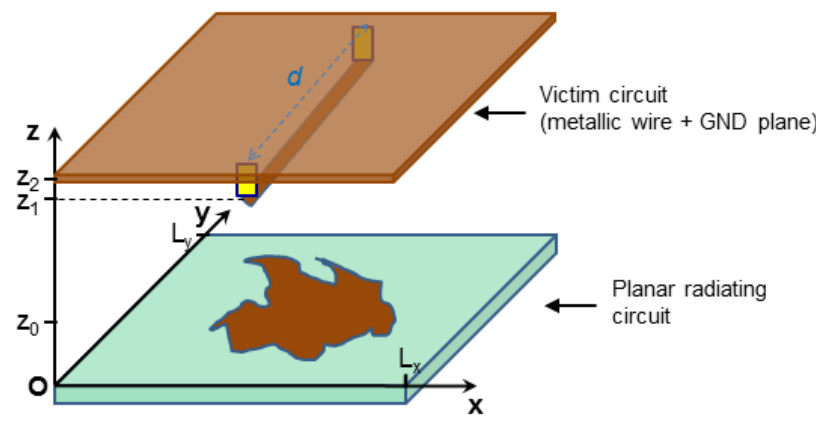

Fig. 1. Radiating circuit and the victim grounded wire system understudy

\section{A. NF/NF Transform}

This NF/NF transform is based on the PWS theory applied to NF scanning [14-15]. For any EM waves generalized as $\vec{X}(x, y, z, t)$ in the $(O x y z)$ system associated with wave vector $\vec{k}(f)=k_{x}(f) \vec{u}_{x}+k_{y}(f) \vec{u}_{y}+k_{z}(f) \vec{u}_{z}$, one recalls that the PWS operation is mathematically expressed as:

$$
\vec{P}_{X}(f)=\frac{1}{2 \pi} \iint_{\infty} \vec{X} e^{j\left(k_{x}(f) x+k_{y}(f) y\right)} d x d y,
$$

and the associated inverse PWS (IPWS) is written as:

$$
\vec{X}(f)=\frac{1}{2 \pi} \iint_{\infty} \vec{P}_{X} e^{-j\left(k_{x}(f) x+k_{y}(f) y\right)} d k_{x} d k_{y} .
$$

The PWS operation enables to transpose the plane wave basic properties as translation $\left(\vec{X}(z)=f\left(\vec{X}\left(z_{0}\right)\right)\right)$ [13] and orthogonality $\left(X_{z}=f\left(X_{x}, X_{y}\right)\right)$ [16] both in frequency- and timedomain to non-uniform NF scanned data by taking into account the evanescent waves. This mathematical operation will be handled for extracting E-field components necessary for the application of the Agrawal model [8] in order to 
compute $u(y=0)$ and $u(y=d)$. We intentionally choose this model herein due to its simplicity to extract the voltage from only the E-NF.

\section{B. Integration of Agrawal Model}

As illustrated by the equivalent circuit sketched in Fig. 2, we need only $E_{x}$ and $E_{z}$ located in the hatched surface area delimited by the wire and the ground plane for extracting the voltages across the TL loads $Z_{L}(0)$ and $Z_{L}(d)$. Those voltages can be determined by integration of elementary voltages $u_{0}(y)$ onto the elementary cells $\mathrm{L}_{\mathrm{u}} \mathrm{C}_{\mathrm{u}}$ (by assuming TL as lossless).
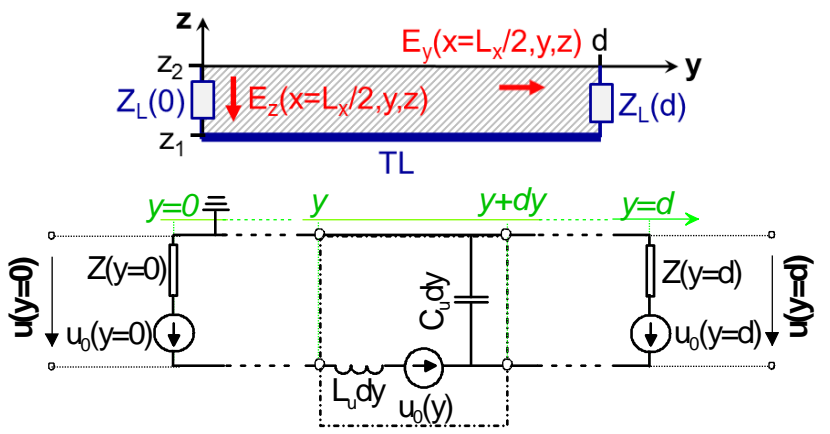

Fig. 2. Circuit configuraiton of the victim line illuminated by essential components of aggression EM field.

The distributed coupling current and voltage along the transmission line can be extracted via [8]:

$$
\left\{\begin{array}{c}
\frac{d u_{0}(y)}{d y}+j \omega L_{u} i(y)=-E_{z}\left(y, z=z_{1}\right) \\
\frac{d i(y)}{d y}+j \omega C_{u} u_{0}(y)=0
\end{array},\right.
$$

with $\omega$ is the radian frequency. By denoting $\rho(y)_{y=0, d}=\left(Z(y)-Z_{c}\right) /\left(Z(y)+Z_{c}\right)$ the reflection coefficients at the extremities of the wire, the coupling voltages are generated from BLT equation [10]:

$\left[\begin{array}{l}u(y=0) \\ u(y=d)\end{array}\right]=\left[\begin{array}{cc}1+\rho_{1} & 0 \\ 0 & 1+\rho_{2}\end{array}\right]\left[\begin{array}{cc}-\rho_{1} & e^{\gamma \cdot d} \\ e^{\gamma \cdot d} & -\rho_{2}\end{array}\right]^{-1}\left[\begin{array}{l}u_{1} / 2 \\ u_{2} / 2\end{array}\right]$,

where $\gamma$ is the TL propagation constant and:

$$
\left\{\begin{array}{c}
u_{1}=\int_{0}^{d} e^{\gamma \cdot y} E_{y}\left(y, z_{1}\right) d y+\int_{z_{2}}^{z_{1}}\left(E_{z}(0, z)-e^{\gamma \cdot d} E_{z}(d, z)\right) d z \\
u_{2}=-\int_{0}^{d} e^{\gamma(d-y)} E_{y}\left(y, z_{1}\right) d y+\int_{z_{2}}^{z_{1}}\left(E_{z}(d, z)-e^{\gamma \cdot d} E_{z}(0, z)\right) d z
\end{array}\right.
$$

\section{Extraction of Time-Frequency Coupling Voltages}

The methodology combining the routine algorithm including the NF/NF transform, BLT equation and FFT/IFFT is summarized in Fig. 3. We determine first the coupling voltage transfer function $T_{v}(j \omega)$. Then, for any excitation signal $u_{e}(t)$, the coupling voltage $u(t, y=\{0, d\})$ are calculated with IFFT of $T_{v}(j \omega) \cdot f f t\left(u_{e}(t)\right)$. Of course the time and frequency parameters should be adequately synchronized to achieve successful convolution results. After implementation of Matlab routine algorithm traducing this work flow, one gets the application discussed in the following section.

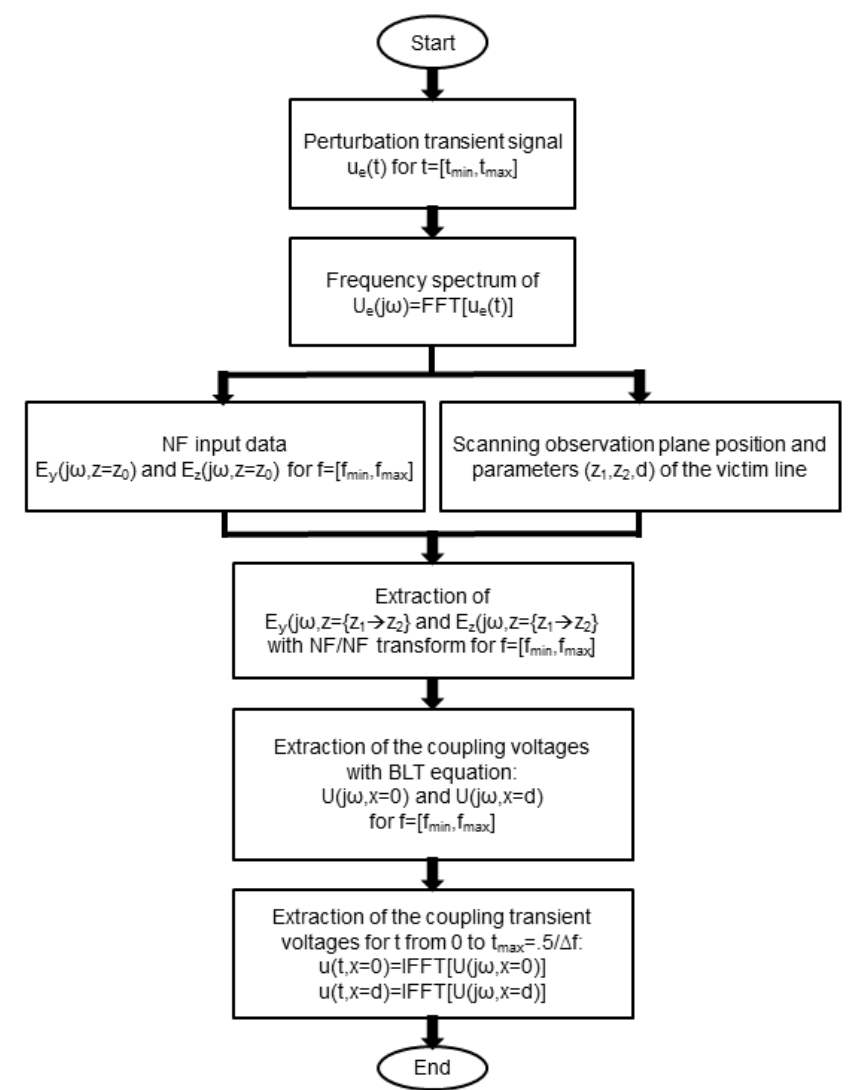

Fig. 3. Work flow illustrating the time-frequency modelling methodology.

\section{COMPUTATION ANALYSIS RESUlTS}

Fig. 4 monitors the photograph of the $8 \mathrm{~cm} \times 10 \mathrm{~cm}$ size Wilkinson power divider (in left), IRSEEM NF scanner considered during the test and the victim grounded wire (in right). The metallic wire loaded by $Z_{L}(0)=Z_{L}(d=3 \mathrm{~cm})=50 \Omega$ is a cylindrical in copper with $d=3 \mathrm{~cm}$ length and $1 \mathrm{~mm}$ diameter placed at $0.7 \mathrm{~mm}$ above the GND plane.
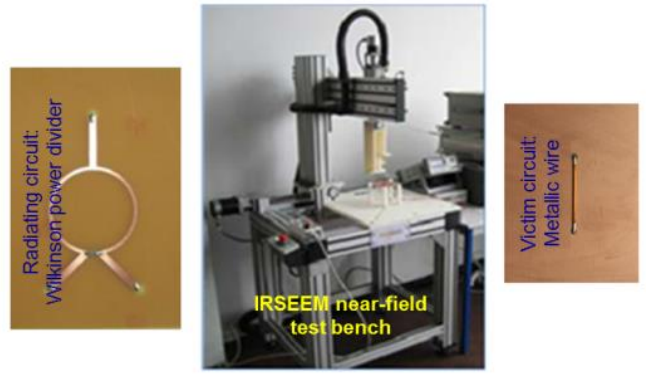

Fig. 4. Photograph the power divier implemented in microstrip technology (in left), IRSEEM NF scanner (in medium) and victim wire (in left).

\section{A. NF/NF Transformed Results}

As aforementioned, E-field scans are necessary for the application of Agrawal model introduced in II.b. So, $E_{x}\left(z_{0}=3 \mathrm{~mm}\right)$ and $E_{y}\left(z_{0}=3 \mathrm{~mm}\right) \mathrm{NF}$ radiated by the circuit shown in Fig. 4 were scanned by using metallic dipoles as NF probes. The scanning was swept from $f_{\min }=0.7 \mathrm{GHz}$ to $f_{\max }=1.3 \mathrm{GHz}$ with $n_{f}=201$ samples. The surface scans are delimited in $\left(x_{\min }=0, x_{\max }=44 \mathrm{~mm}, n_{x}=45 \mathrm{samples}\right)$ and $\left(y_{\min }=0, y_{\max }=62\right.$, 
$n_{y}=42$ samples). Fig. 5 displays the maps of the scanned $E_{x}$ and $E_{y}$ magnitudes and phases @ $f=1 \mathrm{GHz}$. From this initial scan data, $E_{z}\left(z_{0}=3 \mathrm{~mm}\right)$ was extracted based on the NF/NF transform whose amplitude and phase are viewed in Fig. 6. Then, via PWS/IPWS translation operations, the essential fields $E_{y}$ and $E_{z}$ in the surface area between the metallic wire and GND plane were computed. As illustrative results, the $E_{y}(\mathrm{z}=6 \mathrm{~mm}, 11 \mathrm{~mm})$ and $E_{z}(\mathrm{z}=6 \mathrm{~mm}, 11 \mathrm{~mm})$ maps were presented in Figs. 7 and 8. As expected, the amplitude of Efields is inversely proportionnal to the distance between the radiating circuit plane and the victim wire. The E-NF data will be considered for determining the total field including the GND plane reflection via image theory. Then, we apply the routine on BLT equation to determine $\left|T_{v}(f)\right|$ and $\varphi\left(T_{v}(f)\right)$.
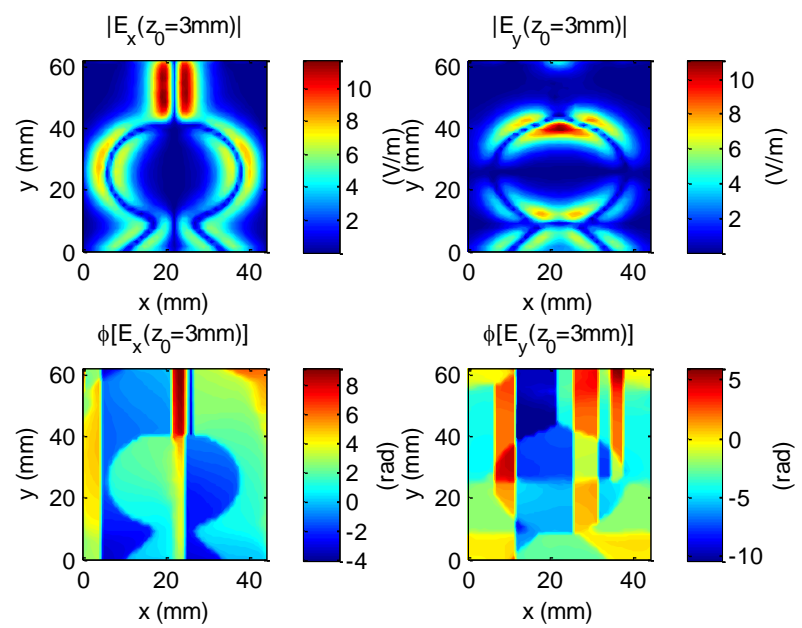

Fig. 5. Maps of scanned $E_{x, y} @\left\{f=1 \mathrm{GHz}, z_{0}=3 \mathrm{~mm}\right\}$.

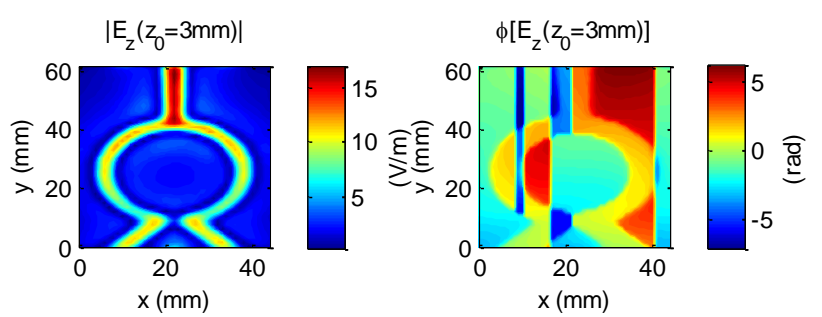

Fig. 6. Map of $E_{z}$ from $E_{x, y} @\left\{f=1 \mathrm{GHz}, \mathrm{z}_{0}=3 \mathrm{~mm}\right\}$.
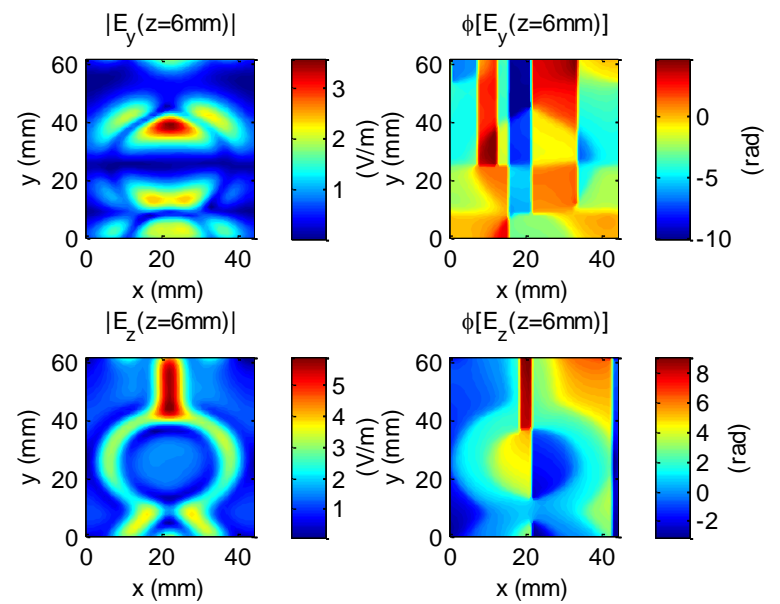

Fig. 7. Maps of $E_{y}$ and $E_{z} @\{f=1 \mathrm{GHz}, z=6 \mathrm{~mm}\}$ from $E_{x, y}\left\{f=1 \mathrm{GHz}, \mathrm{Z}_{0}=3 \mathrm{~mm}\right\}$ by $\mathrm{NF} / \mathrm{NF}$ transform.

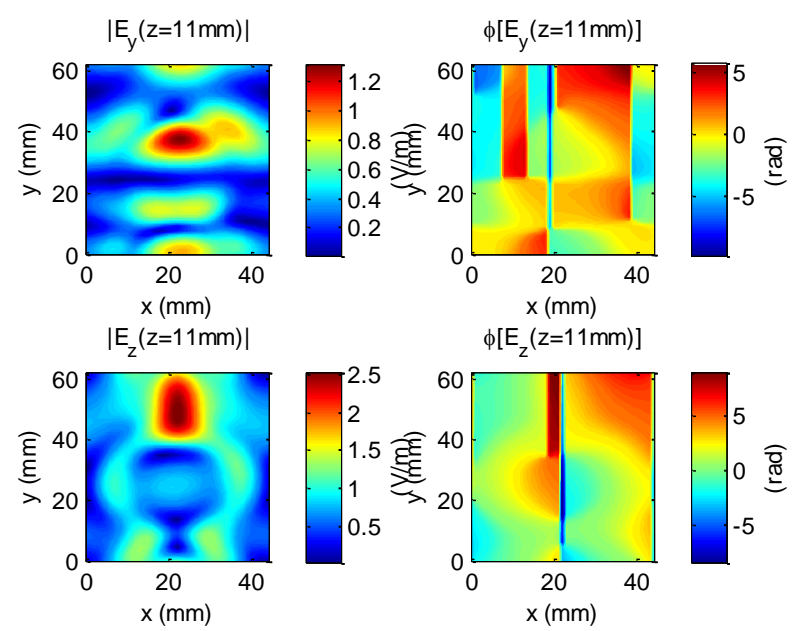

Fig. 8. Maps of $E_{y, z} @\{f=1 \mathrm{GHz}, z=11 \mathrm{~mm}\}$ from $E_{x, y}\left\{f=1 \mathrm{GHz}, \mathrm{z}_{0}=3 \mathrm{~mm}\right\}$ by NF/NF transform.

\section{B. Computed Coupling Voltages Across the Victim Wire}

Figs. 9 and 10 display the frequency plots of $T_{v}$ magnitude and phase respectively, obtained by considering the power divider radiation and the grounded wired system.
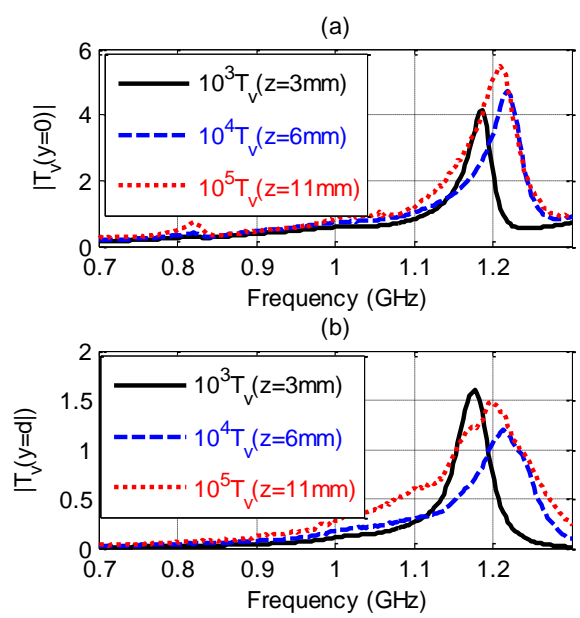

Fig. 9. Coupling voltage transfer function magnitudes.
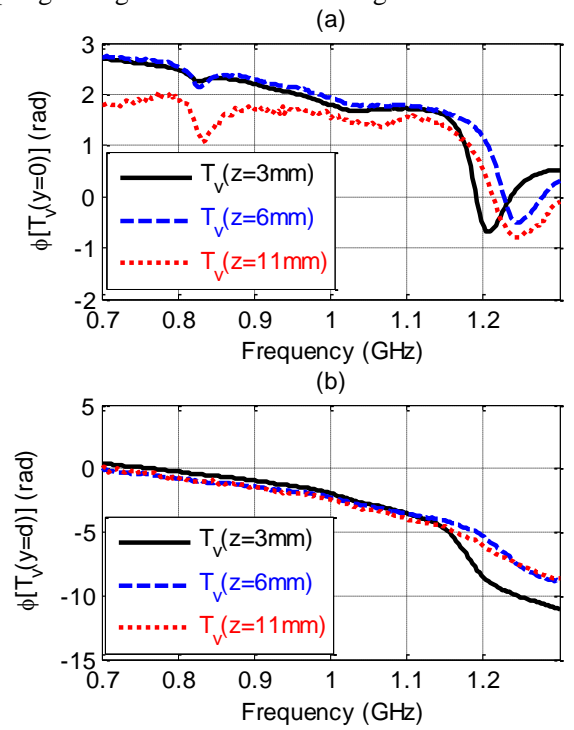

Fig. 10. Coupling voltage transfer function phase shifts. 
The signal $u_{e}$ plotted in Fig. 11 was assigned as transient perturbation. Then, it was extracted $\operatorname{FFT}\left(u_{e}\right)$ from $f_{\min }$ to $f_{\max }$ in order to perform convolution with $T_{v}$. Then, the calculated coupled voltages corresponding to $z=\{3 \mathrm{~mm}, 6 \mathrm{~mm}, 11 \mathrm{~mm}\}$ are plotted in Fig. 12. As we can see the coupled voltages presented amplitude increased from about $2 \mathrm{mV}$ to $25 \mu \mathrm{V}$ when the victim wire is placed in this area. One emphasizes that the CPU time of the whole method implemented into Matlab run with PC equipped by windows 7 having Intel ${ }^{\circledR}$ Core $^{\mathrm{TM}}$ i52467M CPU @1.6GHz 4Go RAM was of about five seconds.
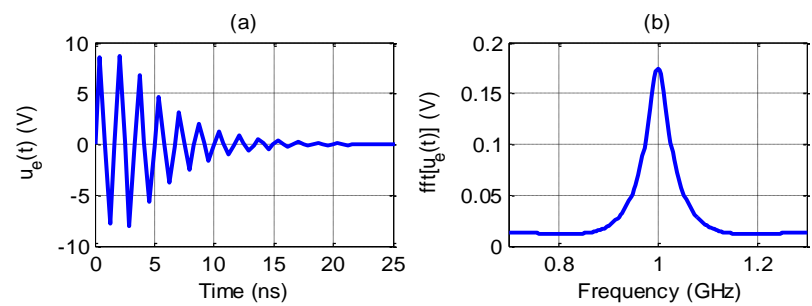

Fig. 11. Time-domain plot (a) and spectrum (b) of the excitation signal.
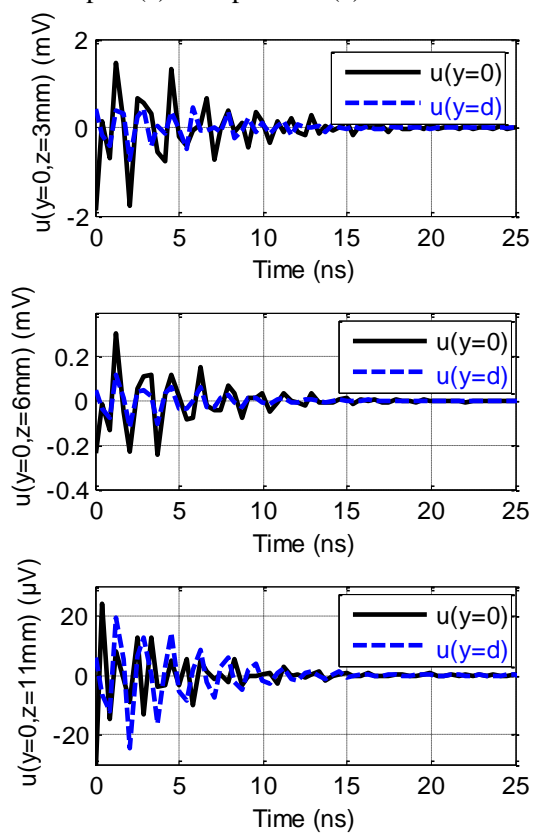

Fig. 12. Extracted transient coupling voltages.

\section{CONCLUSION}

A time-frequency modelling method of near-field coupling between planar circuit and grounded wire is performed. The modelling method is based on the combination of NF/NF transform with PWS theory applied to EM NF radiation, TL coupling BLT equation and FFT/IFFT with an external signal. The routine algorithm was applied to analyse the EM coupling between Wilkinson power divider and metallic wire. Extraction of EM NF in the area of interest from $0.7-$ to- $1.3 \mathrm{GHz}$ was realized from the scanned data. Then, the coupling transfer functions were suggested. Via convolution with transient perturbation, time-domain voltage couplings across the victim wire were determined and discussed.

The model investigated is useful for the analysis of complexity electronic equipment in embedded systems especially for automotive and aeronautic applications with $\mathrm{RF} /$ microwave PCBs located in confined space. It allows a preliminary study on RF/electronic modules under EM radiations and to meet the standards as EN 61000-4-3, IEC 61000-4-4 [4] and EN 55022 [5]. Fast and easy quantitative knowledge on the behavior and EM environment effects for the radiating emitting and immunity can be conducted.

\section{ACKNOWLEDGMENT}

Acknowledgement is made to European Union and Upper Normandy region, France for the support of this research through the European Programme INTERREG IVA FranceChannel-UK by funding project No 4081 entitled "Timedomain EM Charact. and Simul. for EMC appl. (TECS)".

\section{REFERENCES}

[1] R. G. Kaires, "Radiated Emissions from Printed Circuit Board Traces Including the Effect of Vias, as a Function of Source, Termination and Board Characteristics," Proc. of IEEE Int. Symp. on EMC, Denver, CO, pp. 872-877, 24-28 Aug. 1998.

[2] T. Ostermann and B. Deutschmann, "TEM-Cell and Surface Scan to Identify the Electromagnetic Emission of Integrated Circuits," Proc. of 13th ACM Great Lakes Symp. VLSI, Washington, DC, pp. 76-79, 2003.

[3] Y. Liu and B. Ravelo, "Application of Near-Field Emission Processing for Microwave Circuits under Ultra-Short Duration Perturbations," Advanced Electromagnetics, vol. 1, no. 3, pp. 24-40, Oct. 2012.

[4] "Electromagnetic Compatibility (EMC) - Part 4-4: Testing and Measurement Techniques - Electrical Fast Transient/Burst Immunity Test," Standard, EN/IEC 61000-4-4:2012.

[5] "Information Technology Equipment - Radio Disturbance Characteristics - Limits and Methods of Measurement", Standard, EN 55022:2006+A1, 2007.

[6] Y. Kami and R. Sato, "Coupling Model of Crossing Transmission Lines,” IEEE Tran. EMC, vol. EMC-28, pp. 204-210, 1986.

[7] C. D. Taylor and R. S. Sattewhite, "The Response of a Terminated TwoWire Transmission Line Excited by a Nonuniform Electromagnetic Field,” IEEE Tran. Ant. Prop., vol. E, pp. 987-989, 1965.

[8] A. K. Agrawal and H. J. Price, "Transient Response of Multiconductor Transmission Lines Excited by a Non Uniform Electromagnetic Field," IEEE Tran. Ant. Prop., vol. 18, pp. 432- 435, June 1980.

[9] F. Rachidi, "Formulation of the Field to Transmission Line Coupling Equations in Terms of Magnetic Excitation Field," IEEE Tran. EMC, vol. 35, no. 3, pp. 404-407, Aug. 1993.

[10] C. E. Baum, "Generalization of the BLT Equation," Interaction Note, vol. $511,1995$.

[11] E. R. Rajkumar, B. Ravelo, M. Bensetti and P. Fernandez-Lopez, "Application of a Hybrid Model for the Susceptibility of Arbitrary Shape Metallic Wires Disturbed by EM Near-Field Radiated by Electronic Structures,” PIER B, vol. 37, pp. 143-169, 2012.

[12] C. Leseigneur, D. Baudry, B. Ravelo and A. Louis, "Near-field Coupling Model between PCB and Grounded Transmission Line Based on Plane Wave Spectrum,” Eur. Phys. J. Appl. Phys., vol. 64, no. 01 (11001), Oct. 2013, pp. 1-14.

[13] B. Ravelo, Y. Liu and J. B. H. Slama, "Time-Domain Planar NearField/Near-Field Transforms with PWS Method," Eur. Phys. J. Appl. Phys., vol. 53, no. 1 (30701), Feb. 2011, pp. 1-8.

[14] D. T. Paris, W. M. Leach and E. B. Joy, "Basic Theory of ProbeCompensated Near-Field Measurements," IEEE Tran. Ant. Prop., vol. 26, no. 3, May 1978, pp. 373-379.

[15] J. Shi, M. A. Cracraft, K. P. Slattery, M. Yamaguchi and R. E. DuBroff, "Calibration and Compensation of Near-Field Scan Measurements," IEEE Tran. EMC, vol. 47, no. 3, pp. 642-650, Aug. 2005.

[16] Y. Liu, B. Ravelo, A. K. Jastrzebski and J. Ben Hadj Slama, "Calculation of the Time Domain z-Component of the EM-Near-Field from the $x$ - and y-Components," Proc. of 41st EuMC, Manchester, UK, pp. 317-320, 9-14 Oct. 2011. 
